\title{
Efficient Methods For Improving Coding Gains In Concatenated Coding Systems
}

\author{
Paaske, Erik
}

Published in:

Proceedings of IEEE International Symposium on Information Theory

Publication date:

1991

Document Version

Publisher's PDF, also known as Version of record

Link back to DTU Orbit

Citation (APA):

Paaske, E. (1991). Efficient Methods For Improving Coding Gains In Concatenated Coding Systems. In Proceedings of IEEE International Symposium on Information Theory (pp. 297-297). IEEE.

\section{General rights}

Copyright and moral rights for the publications made accessible in the public portal are retained by the authors and/or other copyright owners and it is a condition of accessing publications that users recognise and abide by the legal requirements associated with these rights.

- Users may download and print one copy of any publication from the public portal for the purpose of private study or research.

- You may not further distribute the material or use it for any profit-making activity or commercial gain

- You may freely distribute the URL identifying the publication in the public portal

If you believe that this document breaches copyright please contact us providing details, and we will remove access to the work immediately and investigate your claim. 


\title{
EFFICIENT METHODS FOR IMPROVING CODING GAINS IN CONCATENATED CODING SYSTEMS
}

\author{
Erik Paaske \\ Institute of Circuit Theory and Telecommunication \\ 343. Technical University of Denmark \\ DK-2800 Lyngby, Denmark
}

We consider concatenated coding systems for deep space missions, and in particular we consider means to achieve an improved coding gain compared to the CCSDS recommended system which uses a $(255,223)$ ReedSolomon code over GF (256) as the outer code, and a convolutional rate $R=\frac{1}{2}$ code with memory 6 as the inner code. Viterbi decoding is assumed and a block interleaver with interleaving degrees up to 8 is used between the inner and outer stage.

For the Galileo mission NASA (JPL) achieved an improved coding gain of $1.6 \mathrm{~dB}$ by exchanging the inner convolutional $(n, k, M)=(2,1,6)$ code with a $(4,1,14)$ code, i.e. a code requiring 16,384 states in the decoder.

We have achieved almost the same improvement with a $(4,1,6)$ code, i.e. a code with state complexity equal to the CCSDS recommended code. To achieve the improved gain we allow repeated decoding trials and the Reed Solomon codewords - which are used in a block interleaved structure - to have different numbers of information symbols although the overall number corresponds to the CCSDS recommended number. Furthermore we have selected a code with an improved fall-off at smal signal-to-noise ratios (SNR) at the expense of a small increase in bit-error-rates (BER) at higher SNR's compared to other known $(4,1,6)$ codes.

The decoder operates as follows: In the first pass an ordinary Viterbi decoding is followed by an RS-decoding. For each RS-word the decoding can result in a decoding success, where the possible errors are corrected, or a decoding failure where errors are detected. In the second pass the Viterbi decoder is forced to decode only sequences that agree with the results from the RS-decoding successes. This tends to improve the decoding in such a way that more RS-decoding successes result in the second pass, in particular for codewords which are neighbours to already decoded codewords. The procedure is repeated until all RS-words are decoded or until no improvement is obtained in a pass.
Forced sequence Viterbi decoding is an efficient method to improve the Viterbi decoding [1], and the actual reason for frame losses with ordinary CCSDS interleaving becomes the event that all RS-words in a frame result in decoding failures such that no second pass can be made. This situation is improved by the generalized RS-interleaving where some of the codewords have a greater errorcorrecting ability at the expense of some other codewords with a smaller error-correcting ability. Thus the optimization lies in achieving a "balance" between the power of the forced sequence Viterbi decoding algorithm and the generalized RS-interleaving.

We sum up by concluding that we have achieved an improved coding gain of $1.5 \mathrm{~dB}$ compared to CCSDS recommended system. Our improvement almost equals the improvement obtained by JPL for the Galileo mission, which was achieved using a very complex inner decoder. In contrast our improvement was achieved with a 64 state decoder by

1) Selecting an $R=\frac{1}{4}$ code with a very nice fall-off for small SNR.

2) Using repeated, forced sequence Viterbi decoding and repeated RS decoding trials.

3) Using generalized RS-interleaving without an overall complexity increase.

\section{References}

[1] E. Paaske, "Improved decoding for a concatenated coding system recommended by CCSDS", IEEE Trans. Commun., vol. COM-38, pp. 11381144, Aug. 1990. 